\title{
The Catalytic Product of Pentachlorophenol 4-Monooxygenase is Tetra- chlorohydroquinone rather than Tetrachlorobenzoquinone
}

\author{
Yunyou Su, Lifeng Chen, Brian Bandy and Jian Yang*
} College of Pharmacy and Nutrition, University of Saskatchewan, 110 Science Place, Saskatoon, Saskatchewan, Canada
S7N 5C9, Canada

\begin{abstract}
Pentachlorophenol 4-monooxygenase (PcpB) catalyzes the hydroxylation of pentachlorophenol in the pentachlorophenol biodegradation pathway in Sphingobium chlorophenolicum. Previous studies from two different research groups proposed oppositely that the catalytic product of PcpB was tetrachlorohydroquinone (TCHQ) and tetrachlorobenzoquinone (TCBQ). We re-examined the identity of the catalytic product of PcpB, because TCHQ and TCBQ are present in a redox-equilibrium in aqueous solutions and the chemical reagents NADPH, ethyl acetate and glutathione used for the product detection in the previous studies may shift the redox-equilibrium. In this study, we investigated the effects of $\mathrm{NADPH}$, ethyl acetate and glutathione on the redox-equilibrium and product distribution. Under newly designed experimental conditions, we confirmed unambiguously that the catalytic product of PcpB is TCHQ instead of TCBQ. We also propose that TCBQ may be produced non-specifically by peroxidases within the bacterial cells and that TCBQ reductase (PcpD) might act as a self-protective rather than a PCP-degradation enzyme.
\end{abstract}

\section{INTRODUCTION}

Pentachlorophenol (PCP), a chloroaromatic pesticide widely used to preserve lumber in the last century, is currently listed as one of the major environmental pollutants in North America [1-4]. In spite of being designed to resist biodegradation, PCP can be degraded by a number of soil and aquatic microorganisms such as $S$. chlorophenolicum [5-17]. The PCP biodegradation pathway in S. chlorophenolicum, which is one of the most characterized PCP biodegradation systems, converts PCP to 3-oxoadipate (3-OXO) using five catalytic enzymes [6-17].

The biodegradation of PCP in S. chlorophenolicum is highly inefficient mainly due to the low catalytic activity of pentachlorophenol 4-monooxygenase $(\mathrm{PcpB})$, which is the first and rate-limiting enzyme in the pathway $[6,7,11,12,16]$. $\mathrm{PcpB}$ is a flavin-containing monooxygenase and catalyzes the hydroxylation of PCP using nicotinamide adenine dinucleotide phosphate (NADPH) as a co-substrate $[6,7,11,12,16]$. Previous studies by Xun et al. $[6,7,12,16]$ identified tetrachlorohydroquinone (TCHQ) as the catalytic product of PcpB (Fig. 1). Later Dai et al. [11] reported that the catalytic product of $\mathrm{PcpB}$ was tetrachlorobenzoquinone (TCBQ) rather than TCHQ (Fig. 1) and that the reduction of TCBQ into TCHQ was catalyzed by a new enzyme, tetrachlorobenzoquinone reductase $(\mathrm{PcpD})$, which was encoded by gene $p c p D$. Although TCBQ is now commonly accepted as the catalytic product of $\mathrm{PcpB}$, we have a concern about the identity of the catalytic product of PcpB because the experiments undertaken by neither research group were sufficient to support their conclusion.

*Address correspondence to this author at the College of Pharmacy and Nutrition, University of Saskatchewan, 110 Science Place, Saskatoon, Saskatchewan, Canada S7N 5C9; Canada; Tel: 1-306-966-6361; Fax: 1-306966-6377; E-mail: jiy129@mail.usask.ca

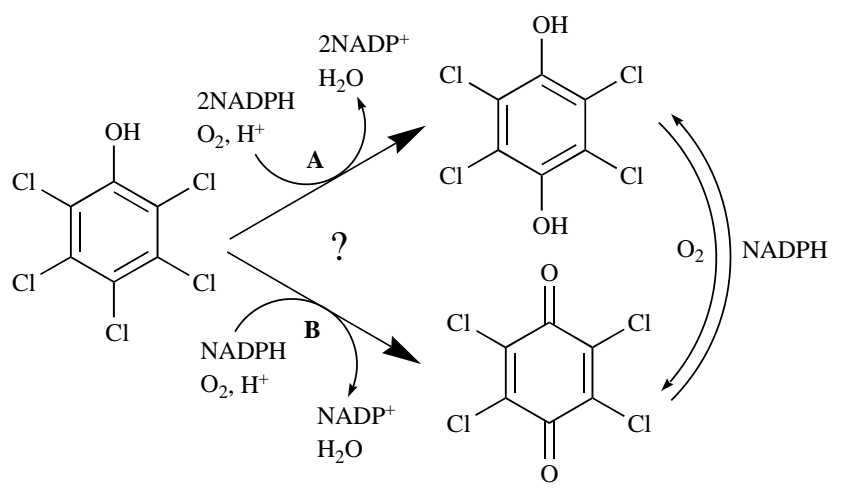

Fig. (1). The proposed catalytic reaction of PcpB. (A). Reported by Xun et al. $[6,7,12,16]$. (B). Reported by Dai et al. [11].

TCHQ and TCBQ are present in a redox-equilibrium in aqueous solutions except under rigorous anaerobic conditions. The redox-equilibrium can be easily shifted by reducing agents, oxidizing agents, and any other agents reactive with either TCHQ or TCBQ. Excessive NADPH used by Xun et al. [16] would non-enzymatically reduce TCBQ into TCHQ [18] if it were the catalytic product of PcpB, leaving only TCHQ detectable regardless the catalytic product of PcpB was TCHQ or TCBQ. On the other hand, ethyl acetate extraction and product trapping with glutathione (GSH) used by Dai et al. [11] were equally questionable. Contrary to hydroquinones, benzoquinones are usually poorly soluble in aqueous solutions [19]. Thus the extraction of the aqueous solution with ethyl acetate would favor oxidation of TCHQ, a hydroquinone, to TCBQ, a benzoquinone. As for the product trapping, glutathione (GSH) is a nucleophilic compound and should react quickly with the electrophilic TCBQ. Therefore, both ethyl acetate and GSH can shift the redoxequilibrium towards the TCHQ side. In summary, it is practically impossible to distinguish TCHQ from TCBQ unambiguously under the experimental conditions adopted by either research group. 
In order to confirm the identity of the catalytic product of PcpB, we first studied the effects of NADPH, ethyl acetate and GSH on the redox-equilibrium between TCHQ and TCBQ. Based on the study results, we re-designed the experimental conditions for the hydroxylation reaction catalyzed by PcpB. TCHQ rather than TCBQ was confirmed to be the catalytic product of $\mathrm{PcpB}$. In addition, we showed that peroxidases, which did not require PCP induction and were constitutively expressed within $S$. chlorophenolicum strain ATCC 39723, might be involved in the production of TCBQ from both PCP and TCHQ.

\section{MATERIALS AND METHODOLOGY}

\section{Bacterial Culture Conditions}

S. chlorophenolicum strain ATCC 39723, purchased from American Type Culture Collection (Manassas, USA), was cultured in mineral media $\left(\mathrm{K}_{2} \mathrm{HPO}_{4} 0.65 \mathrm{~g}, \mathrm{KH}_{2} \mathrm{PO}_{4} 0.19 \mathrm{~g}\right.$, $\mathrm{MgSO}_{4} 0.1 \mathrm{~g}, \mathrm{NaCl} 2.0 \mathrm{~g}$, glutamic acid $4.0 \mathrm{~g}$, and $\mathrm{FeSO}_{4} 3$ $\mathrm{mg}$ ). After inoculation with $1 \mathrm{~mL}$ of freshly grown cells, the bacterium was grown in $1 \mathrm{~L}$ of mineral media at $30{ }^{\circ} \mathrm{C}$ for 4 $\mathrm{d}$ before any experiment was undertaken.

\section{Expression and Purification of Recombinant His $_{6}$-tagged PcpB}

The Escherichia coli M15 cells over-expressing recombinant $\mathrm{His}_{6}-\mathrm{PcpB}$ were kindly provided by Dr. Shelley D. Copley of the University of Colorado at Boulder. The expression of PcpB was induced by isopropyl $\beta$-D-1-thiogalactopyranoside (IPTG) with a final concentration of $100 \mu \mathrm{M}$. After induction, the cells were grown for another $4 \mathrm{~h}$ before being harvested by centrifugation at 5,000 $\mathrm{g}$ for $20 \mathrm{~min}$. The cell pellets obtained from $1 \mathrm{~L}$ cell cultures were stored at -80 ${ }^{\circ} \mathrm{C}$. The purification of $\mathrm{PcpB}$ was performed at $4{ }^{\circ} \mathrm{C}$ using affinity chromatography. Briefly, a frozen pellet from $1 \mathrm{~L}$ of cell culture was suspended in $50 \mathrm{~mL}$ of the lysis buffer $(50$ $\mathrm{mM}$ Tris- $\mathrm{HCl}, \mathrm{pH} 7.7,0.25 \mathrm{mM}$ phenylmethanesulfonyl fluoride (PMSF), $1 \mu \mathrm{M}$ pepstatin A, and $40 \mathrm{mg}$ of lysozyme) and incubated with gentle rotation for $30 \mathrm{~min}$. The cells were then subjected to further disruption by sonication using a Sonifier ${ }^{\mathrm{TM}} 150$ sonicator. The cell lysate was centrifuged at $20,000 \mathrm{~g}$ for $30 \mathrm{~min}$. The supernatant was mixed with $5 \mathrm{~mL}$ of Ni-NTA agarose media and shaken for $2 \mathrm{~h}$ before being packed into a column and washed thoroughly with the washing buffer (50 $\mathrm{mM}$ phosphate buffer, $\mathrm{pH} 7.7,50 \mathrm{mM}$ imidazole, $0.3 \mathrm{M} \mathrm{NaCl}, 0.25 \mathrm{mM} \mathrm{PMSF}$, and $1 \mu \mathrm{M}$ pepstatin A) at a flow rate of $2 \mathrm{~mL} / \mathrm{min}$ until the elute $\mathrm{UV}$ absorbance was approximately zero. PcpB was eluted with $30 \mathrm{~mL}$ of the elution buffer $(50 \mathrm{mM}$ phosphate buffer, $\mathrm{pH} 7.7,0.3 \mathrm{M} \mathrm{NaCl}$, $250 \mathrm{mM}$ imidazole, $0.25 \mathrm{mM}$ PMSF, and $1 \mu \mathrm{M}$ pepstatin $\mathrm{A})$. The purity of $\mathrm{PcpB}$ in the elution fractions was examined on a $12 \%$ SDS-PAGE gel. Fractions containing pure PcpB were combined, buffer-exchanged to storing buffer $(20 \mathrm{mM}$ phosphate buffer, $\mathrm{pH} 7.0,0.25 \mathrm{mM}$ PMSF, 5\% glycerol), concentrated to $15 \mathrm{mg} / \mathrm{mL}$, and stored at $-80^{\circ} \mathrm{C}$.

\section{Calibration Curves for PCP, TCHQ and TCBQ}

All experiments involved in the current study, including the standard curve calibrations, were undertaken in duplicate. PCP, TCHQ and TCHQ with higher than 98\% purity were purchased from Sigma-Aldrich Canada (Oakville, Canada).
To calibrate the standard curve for each compound, sample solutions with concentrations at $200 \mu \mathrm{M}, 100 \mu \mathrm{M}, 50 \mu \mathrm{M}$, and $25 \mu \mathrm{M}$ were prepared by serial dilutions with deionized distilled water. The samples were then analyzed by HPLC on an Alltech C8 column. $30 \mu \mathrm{L}$ of each sample was injected into the column and eluted with the mobile phase solvent of $60 \%$ acetonitrile and $40 \%$ acetic acid $(0.1 \%)$ at $1 \mathrm{~mL} / \mathrm{min}$. The retention times for TCHQ, TCBQ and PCP were identified to be $7 \mathrm{~min}, 9.5 \mathrm{~min}$, and $17.5 \mathrm{~min}$, respectively. The area of the absorption peak for each sample on the HPLC histogram was calculated. A standard curve of each compound was obtained by a linear fit between the sample concentration and peak area. Quantification of PCP, TCHQ or TCBQ in other experimental samples was carried out by comparing their peak areas on the HPLC histogram against the respective standard curve.

\section{Reduction of TCBQ by NADPH}

NADPH was added into $100 \mu \mathrm{L}$ of $100 \mu \mathrm{M}$ TCBQ water solutions to final concentrations of $0 \mu \mathrm{M}, 50 \mu \mathrm{M}, 100 \mu \mathrm{M}$, $250 \mu \mathrm{M}$, and $500 \mu \mathrm{M}$. The solutions were then allowed to sit at room temperature $\left(\sim 23^{\circ} \mathrm{C}\right)$ from 1 to $5 \mathrm{~min}$ before immediate loading on the Alltech C8 column for HPLC analysis. Being aware of that no chemicals would stop the reduction of TCBQ by NADPH without interfering with the redoxequilibrium, the reaction samples were analyzed by HPLC one at a time.

\section{Effects of Ethyl Acetate on the Redox-Equilibrium}

1-mL solutions containing $100 \mu \mathrm{M}$ TCHQ, $100 \mu \mathrm{M}$ TCBQ, and $100 \mu \mathrm{M}$ of both TCHQ and TCBQ were prepared in $50 \mathrm{mM}$ phosphate buffer ( $\mathrm{pH} 7.0)$. The UV-visible absorption spectra of the solutions were recorded on an Agilent 8453 diode array spectrophotometer (Agilent Technologies, Mississauga, Canada) at $25{ }^{\circ} \mathrm{C}$ using a $1-\mathrm{mL}$ quartz cuvette of $10 \mathrm{~mm}$ path length. The UV-visible absorption spectra were baseline-corrected with the phosphate buffer. The solutions were then extracted with $1 \mathrm{~mL}$ ethyl acetate. The UV-visible absorption spectra of the extractions were also recorded with the baseline corrected with ethyl acetate.

\section{Effects of GSH on the Redox-Equilibrium}

GSH was added into $100 \mu \mathrm{L}$ solution of $100 \mu \mathrm{M}$ TCHQ in $50 \mathrm{mM}$ phosphate buffer, $\mathrm{pH} 7.0$, with final concentrations of $0 \mu \mathrm{M}, 50 \mu \mathrm{M}, 100 \mu \mathrm{M}, 200 \mu \mathrm{M}$, and $500 \mu \mathrm{M}$. The solutions were incubated at room temperature $\left(\sim 23^{\circ} \mathrm{C}\right)$ from 1 to 5 min before immediate loading on the Alltech $\mathrm{C} 8$ column for HPLC analysis. As with the reduction of TCBQ by $\mathrm{NADPH}$, the reaction samples in this study were analyzed by HPLC one at a time.

\section{Measurement of Oxygen Consumption Rate}

The oxygen consumption rate was determined in duplicate in a $1-\mathrm{mL}$ enclosed system using a Hansatech oxytherm electrode unit (Hansatech Instruments, Norfolk, England) at $23.5^{\circ} \mathrm{C}$. First, $1 \mathrm{~mL}$ of $50 \mathrm{mM}$ phosphate buffer, $\mathrm{pH} 7.0$, saturated with oxygen was placed into the electrode unit and the chamber was closed with the syringe-port plunger. Then, GSH was added to the unit with final concentrations of 0 $\mu \mathrm{M}, 50 \mu \mathrm{M}, 100 \mu \mathrm{M}, 200 \mu \mathrm{M}, 500 \mu \mathrm{M}, 1 \mathrm{mM}$, or $2 \mathrm{mM}$. Finally, TCHQ was injected into the unit with a final concen- 
tration of $100 \mu \mathrm{M}$. The oxygen consumption rate was measured after each injection.

\section{Detection of the Catalytic Product of PcpB}

A $100 \mu \mathrm{L}$ reaction solution containing $100 \mu \mathrm{M}$ of PcpB and NADPH, respectively, was incubated at room temperature for at least $1 \mathrm{~min}$ prior to the addition of PCP to initiate the catalytic reaction of $\mathrm{PcpB}$ with a final concentration of $200 \mu \mathrm{M}$. The reaction was allowed to proceed for $1 \mathrm{~min}$ before being stopped either by quenching with $1 \mathrm{M} \mathrm{HCl}$ or acetonitrile containing $0.1 \mathrm{M} \mathrm{HCl}$ or by quick centrifugation at $5,000 \mathrm{rpm}$ for 30 seconds with an Amicon ultra-4 $10 \mathrm{kDa}$ filtration unit. The quenched samples were quickly centrifuged at $13,000 \mathrm{rpm}$ for 30 seconds on a VWR Galaxy ${ }^{\mathrm{TM}}$ $14 \mathrm{D}$ microcentrifuge. $30 \mu \mathrm{L}$ of the supernatant from the quenched samples or the filtrate from the Amicon centrifugation samples was immediately injected into the Alltech C8 column for HPLC analysis by eluting with the mobile phase solvent $(60 \%$ acetonitrile and $40 \%$ acetic acid $0.1 \%$ ) at 1 $\mathrm{mL} / \mathrm{min}$.

\section{Structural Model of PcpB}

The crystal structure of the aromatic hydroxylase from Streptomyces strain pga64 (PDB ID: 2qa1) [20] was identified as the template to build the homology model of PcpB from the protein-protein BLAST (blastp) search against the Protein Data Bank using the amino acid sequence of PcpB. Pair-wise comparative sequence alignment between PcpB and the aromatic hydroxylase was done by ClustalW [21]. Ten PcpD initial models were built using software MODELLER V8.1 [22] with default parameters. The geometry and energy criteria for each initial model were evaluated by the programs PROCHECK [23], ProSa II [24] and Verify3D [25]. The model with best geometry and lowest energy was selected as the final structural model of PcpB. Energy minimization was not applied to the final model.

\section{Peroxidase Activity Assay}

The peroxidase activity was assayed using the peroxidase/catechol color reaction method. Briefly, $1.5 \mathrm{~mL}$ of fresh cell culture of S. chlorophenolicum strain ATCC 39723 or $300 \mu \mathrm{L}$ of the supernatant from the lysate of $5 \mathrm{~mL}$ cell culture was added into a $1.5-\mathrm{mL}$ reaction mixture containing $1 \%$ pyrocatechol and $1.5 \% \mathrm{H}_{2} \mathrm{O}_{2}$. The reaction was allowed to proceed for $5 \mathrm{~min}$ at room temperature $\left(\sim 23^{\circ} \mathrm{C}\right)$ before the color reaction was recorded.

\section{RESULTS}

\section{NADPH Rapidly Reduces TCBQ to TCHQ}

The non-enzymatic reduction of TCBQ by NADPH was studied at room temperature under four different molar ratios of NADPH and TCBQ. Both TCHQ and TCBQ were detected by high performance liquid chromatography (HPLC). Because either phosphate buffer ( $\mathrm{pH}$ 7.0) or Tris-HCl buffer ( $\mathrm{pH}$ 7.0) interfered with the detection of TCHQ by generating a strong solvent-front peak, the reduction reaction was undertaken in de-ionized distilled water $(\mathrm{pH}$ 6.8). As shown in Fig. (2), the reduction of TCBQ by NADPH was rapid at all four molar ratios. Reestablishment of the redox-equili- brium was achieved in less than $1 \mathrm{~min}$. When the molar ratio was 0.5 or 1 , approximately $50-65 \%$ of TCBQ was reduced to TCHQ. When the molar ratio was 2.5 or higher, almost all TCBQ was reduced to TCHQ. Therefore, in order to unambiguously confirm the identity of the catalytic product of PcpB, the molar ratio between NADPH and the product should always be less than 1 in the reaction system.

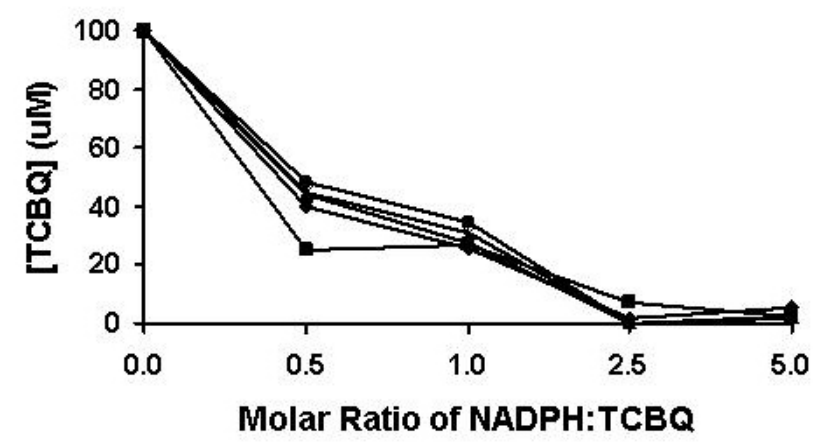

Fig. (2). Reduction of TCBQ by NADPH under different molar ratios between NADPH and TCBQ. The reduction reaction was monitored from 1 to $5 \mathrm{~min}$. The results at the 1, 2, 3, 4, and $5 \mathrm{~min}$ were represented by solid square, solid diamond, solid triangle, asterisk, and solid circle, respectively.
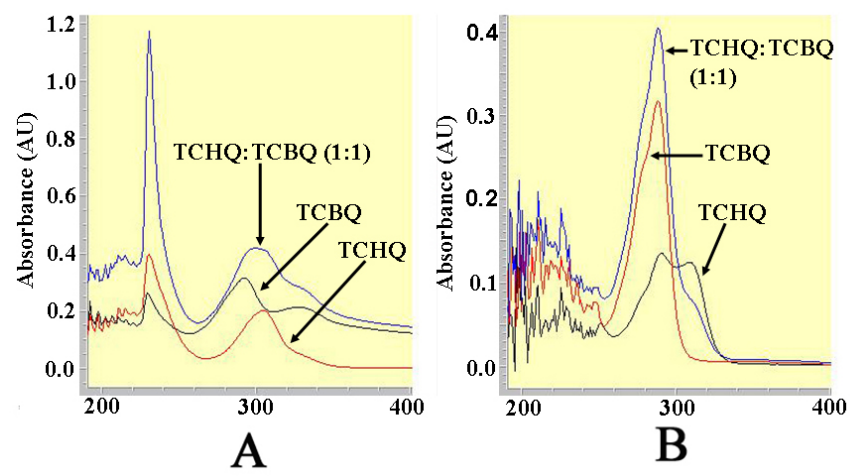

Fig. (3). The UV-visible spectra for the 1-mL solutions containing $100 \mu \mathrm{M}$ TCHQ, $100 \mu \mathrm{M}$ TCBQ, and $100 \mu \mathrm{M}$ of both TCHQ and TCBQ, respectively, in either $50 \mathrm{mM}$ phosphate buffer, $\mathrm{pH} 7.0$ (A) or ethyl acetate extract (B).

\section{Ethyl Acetate Extraction Increased the Oxidation of TCHQ}

Because ethyl acetate extraction may have influenced previous results [11], we investigated the effect of ethyl acetate extraction on the redox-equilibrium between TCHQ and TCBQ using UV-visible spectroscopy. As shown in Fig. (3), the solution containing $100 \mu \mathrm{M}$ TCHQ in $50 \mathrm{mM}$ phosphate buffer exhibited a bell-shaped absorption peak centered at $304 \mathrm{~nm}$; whereas the bell-shaped absorption peak for the 100 $\mu \mathrm{M}$ TCBQ solution was centered at $292 \mathrm{~nm}$. The solution containing $100 \mu \mathrm{M}$ of both TCHQ and TCBQ showed a much larger peak centered at $300 \mathrm{~nm}$, which could be obviously viewed as a summation of the respective absorption peaks for TCHQ and TCBQ. The ethyl acetate extract of the $100 \mu \mathrm{M}$ TCBQ solution gave a narrower absorption peak centered at $292 \mathrm{~nm}$ (Fig. 3). However, the ethyl acetate extract of the $100 \mu \mathrm{M}$ TCHQ solution gave two absorption peaks with maxima at 292 and $304 \mathrm{~nm}$; and the ethyl acetate extract of the solution containing $100 \mu \mathrm{M}$ TCHQ and 100 
$\mu \mathrm{M}$ TCBQ showed a stronger absorption at $292 \mathrm{~nm}$ than the extract from $100 \mu \mathrm{M}$ TCBQ solution and a weaker absorption at $304 \mathrm{~nm}$ than the extract from $100 \mu \mathrm{M}$ TCHQ solution (Fig. 3). These observations strongly suggested that TCHQ had been oxidized during the ethyl acetate extraction, and the extent of oxidation could approach $100 \%$.

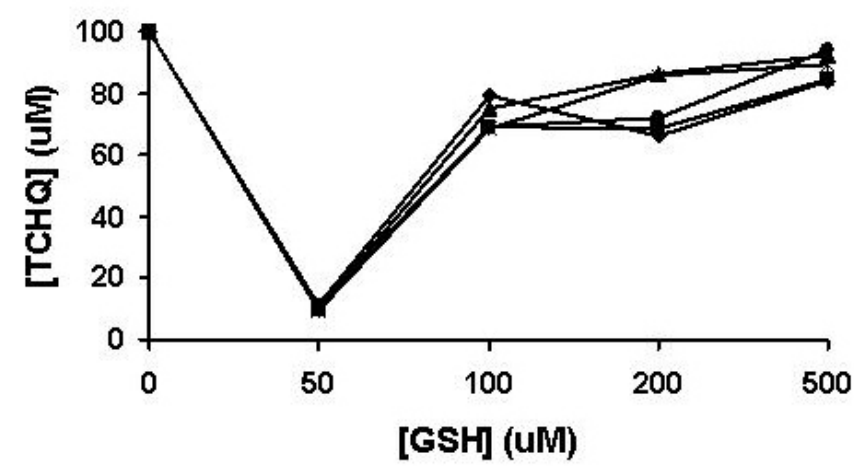

Fig. (4). The effects of GSH on the redox-equilibrium between TCHQ and TCBQ. The reaction was monitored from 1 to $5 \mathrm{~min}$. The results at the 1, 2, 3, 4, and 5 min were shown in solid square, solid diamond, solid triangle, asterisk, and solid circle, respectively.

\section{GSH Shifted the Redox-Equilibrium Towards TCBQ}

As a strong nucleophile, GSH may react rapidly with any electrophilic TCBQ formed through TCHQ oxidation to form GS-TriCBQ, dragging the redox-equilibrium towards TCBQ. Thus, we quantified the effects of GSH on the redoxequilibrium by adding GSH into $100 \mu \mathrm{M}$ TCHQ water solution at five different concentrations using an HPLC method (Fig. 4). GSH was indeed capable of shifting the redoxequilibrium to the TCBQ side and re-establishment of the redox-equilibrium occurred within $1 \mathrm{~min}$. At $50 \mu \mathrm{M} \mathrm{GSH}$, as much as $90 \%$ of TCHQ was converted to TCBQ, GSTriCBQ or tetrachlorobenzosemiquinone. As GSH concentration was $100 \mu \mathrm{M}$ or higher, only about $10-30 \%$ of TCHQ was converted. This is likely due to that the reaction system was in a stronger reducing environment and the oxidation of TCHQ to TCBQ was decreased. In order to confirm this rationale, we measured the oxygen consumption rate in a $1-\mathrm{mL}$ enclosed system containing GSH and TCHQ in $50 \mathrm{mM}$ phosphate buffer, $\mathrm{pH}$ 7.0. Addition of GSH into the phosphate buffer solution produced very little oxygen consumption (data not shown). However, subsequent addition of TCHQ into the phosphate buffer solution increased the oxygen consumption rate dramatically, ranging from 3.0 $\mu \mathrm{M} / \mathrm{min}$ at $2 \mathrm{mM}$ GSH to $9.5 \mu \mathrm{M} / \mathrm{min}$ at $200 \mu \mathrm{M}$ GSH (Table 1). It is obvious that the oxidation of TCHQ was much slower at higher GSH concentrations. This observation is consistent with the above HPLC analysis. Therefore, any nucleophilic compound such as GSH, which can shift the redox-equilibrium towards TCBQ, should be avoided in the characterization of PcpB.

\section{TCHQ Rather Than TCBQ was the Catalytic Product of PсpB}

Contrary to the claim by Dai et al. [11] that TCHQ and TCBQ were usually co-eluted on HPLC, previous studies by Tjeerdema and Crosby [26] and our group showed that PCP,
Table 1. Oxygen Consumption Rate (Average \pm Standard Deviation of two Independent Measurements) from $100 \mu M$ TCHQ Incubated in an Enclosed Reaction System with Different GSH Concentrations at 23.5 ${ }^{\circ} \mathrm{C}$

\begin{tabular}{|c|c|}
\hline GSH $(\mu \mathbf{M})$ & Oxygen Consumption $(\mu \mathbf{M} / \mathbf{m i n})$ \\
\hline \hline 0 & $5.4 \pm 0.3$ \\
\hline 50 & $9.1 \pm 0.1$ \\
\hline 100 & $8.1 \pm 0.4$ \\
\hline 200 & $9.5 \pm 0.3$ \\
\hline 500 & $6.3 \pm 0.3$ \\
\hline 1000 & $4.2 \pm 0.5$ \\
\hline 2000 & $3.0 \pm 0.3$ \\
\hline
\end{tabular}

TCHQ and TCBQ could be easily separated by HPLC. Therefore, we decided to adapt the HPLC method to characterize the catalytic product of PcpB.

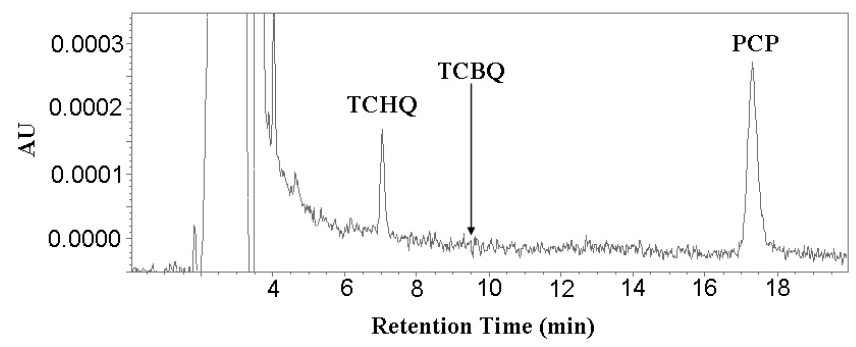

Fig. (5). HPLC analysis of the catalytic product of PcpB. The retention time for TCBQ $(9.5 \mathrm{~min})$ was indicated by an arrow in the histogram.

We first incubated $200 \mu \mathrm{L}$ reaction mixture containing $100 \mu \mathrm{M}$ PcpB and $100 \mu \mathrm{M}$ NADPH at room temperature for at least 1 minute to ensure sufficient binding of NADPH to PcpB and reduction of the flavin. Unbound NADPH should therefore be present to a minimum amount in the reaction mixture. PCP, with the final concentration at $200 \mu \mathrm{M}$, was then added to the reaction mixture to initiate the catalytic reaction of PcpB for $1 \mathrm{~min}$ before the reaction was quenched with $1 \mathrm{M} \mathrm{HCl}$. The quenched reaction mixture was immediately centrifuged at $13,000 \mathrm{rpm}$ for $0.5 \mathrm{~min}$ and the supernatant was immediately loaded onto an Alltech C8 column for HPLC analysis. Under the current experimental conditions (equimolar enzyme:NADPH and excess PCP), NADPH would predominantly react with $\mathrm{PCP}$, leaving the molar ratio between the un-reacted NADPH and the catalytic product of PcpB far below 1. Thus, the catalytic product of PcpB would be detected unambiguously no matter if it was TCHQ or TCBQ. As shown in Fig. (5), the HPLC histogram clearly showed the absorption peaks for TCHQ and PCP. But no trace of TCBQ was detected. In addition, the absorption peaks for both TCHQ and PCP were small, implying the small molecules bound significantly to the viscous gel of the denatured PcpB due to the large amount of enzyme used in the reaction and/or precipitated out due to lower solubility at acidic $\mathrm{pH}$ after quenching with $\mathrm{HCl}$. In order to examine the possibility that TCBQ was the catalytic product of PcpB and 
completely precipitated out and/or bound to the denatured PcpB during the quenching, we repeated the above experiment by stopping the reaction either with $0.1 \mathrm{M} \mathrm{HCl}$ in acetonitrile as the quenching reagent to increase the presence of TCBQ in the supernatant or with the filtration method using an Amicon centrifugal filter unit with molecular weight cutoff of $10 \mathrm{kDa}$. However, we still could not detect any TCBQ in the reaction mixture. We observed that the absorption peak for PCP in the Amicon filtrate was still small, suggesting that PCP bound specifically and/or non-specifically to PcpB because of the large amount of enzyme used. In addition, that the absorption peak for TCHQ in the filtrate was also small suggests that $\mathrm{PcpB}$, its catalytic product, and flavin (either FMN or FAD) were likely present as a ternary complex, in which TCHQ could be trapped much easier by GSH to form GS-TriCBQ.

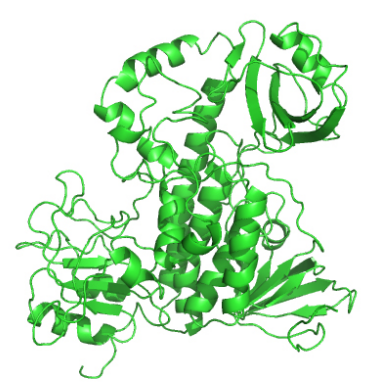

A

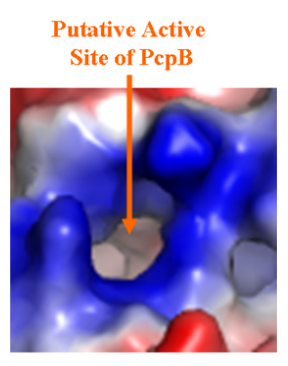

B
Fig. (6). Homology structural model of PcpB. (A). A ribbon representation. (B). Electrostatic potential distribution at the proposed active site by Nakamura et al. [27].

To further investigate the catalytic mechanism, a structural model of PcpB was constructed by homology modeling using the coordinates of the aromatic hydroxylase from Streptomyces strain pga64 (PDB ID: 2qa1) as the template [20]. The active site of PcpB, as defined by Nakamura et al. [27], was highly positively charged (Fig. 6B). The positive electrostatic potentials make it favorable for PcpB to produce TCHQ instead of TCBQ, because the electrophilic TCBQ is not stable in a positively charged environment and the reaction catalyzed by PcpB would have to cross a much higher energy barrier if the catalytic product were TCBQ.

\section{DISCUSSION}

In the current studies, we showed that reducing agent NADPH rapidly reduced TCBQ to TCHQ (Fig. 2). To confirm the identity of the catalytic product of $\mathrm{PcpB}$, the experiment should be designed carefully to ensure that the unreacted NADPH was less than the catalytic product in the reaction system. Although Xun et al. [7] used the substrates NADPH and PCP at 1:1 ratio in their initial characterization of PcpB, the low catalytic activity of PcpB resulted in the molar ratio between NADPH and the catalytic product of $\mathrm{PcpB}$ being much higher than 1 at any time during the reaction. The inefficiency of PcpB led Xun et al. to use a much higher molar ratio $(16,000)$ between NADPH and PCP in their subsequent studies on PcpB [16]. However, under either circumstance, only TCHQ would be identified due to the high molar ratio between NADPH and the product of PcpB regardless of whether the initial product was TCHQ or TCBQ.

Dai et al. provided two key pieces of evidence to support TCBQ as the catalytic product of PcpB [11]. The first piece of evidence was the identification of TCBQ by gas chromatography-mass spectrometry (GC/MS) from the ethyl acetate extract of the PcpB reaction mixture. The ethyl acetate extraction step was reported to be necessary in the GC/MS detection [11]. As described in the introduction section, benzoquinones are less soluble than hydroquinones in aqueous solutions [19] and organic solvent extraction may increase the oxidation of hydroquinones to the corresponding benzoquinones. In the current studies we showed that ethyl acetate extraction increased the oxidation of TCHQ to TCBQ (Fig. 3). Therefore, the ethyl acetate extraction experiment undertaken by Dai et al. [11] was not sufficient to support TCBQ as the catalytic product of PcpB. The second piece of evidence was the formation of 2,3,5-trichloro-6-S-glutathionylbenzoquinone (GS-TriCBQ) upon adding GSH to the PcpB reaction mixture [11]. However, the current studies also showed that GSH shifted the redox equilibrium towards TCBQ and the oxidation of TCHQ was slower at higher GSH concentrations (Fig. 4 and Table 1). Dai et al. reported a $95 \%$ conversion rate for PCP by using $2 \mathrm{mM} \mathrm{GSH}$ to trap the catalytic product of $\mathrm{PcpB}$ [11]. This conversion rate would be much higher than our observation reported above if TCHQ were the catalytic product of PcpB. But we could not conclude TCBQ as the catalytic product of PcpB either, because the high conversion rate could have been obtained with TCHQ as the catalytic product of PcpB for the following reasons. First, the reaction carried out by Dai et al. was at 37 ${ }^{\circ} \mathrm{C}$; whereas ours was only at room temperature $\left(\sim 23{ }^{\circ} \mathrm{C}\right)$. The oxidation of TCHQ to TCBQ would be more than twice as fast at $37^{\circ} \mathrm{C}$. Secondly, the reaction undertaken by Dai et al. was at $\mathrm{pH} 8.0$; whereas our experiment was done at $\mathrm{pH}$ 6.8. TCHQ would be oxidized much faster in alkaline solutions than in acidic solutions [28]. Finally, the usage of a large amount of PcpB in the reaction by Dai et al. might result in the formation of the transient state ternary complex of $\mathrm{PcpB}$, the catalytic product, and flavin. GSH could directly react with the ternary complex to form GS-TriCBQ, which would be much faster than first shifting the redoxequilibrium towards the TCBQ side and then reacting with the TCBQ. Thus, trapping the catalytic product of PcpB by GSH is unlikely to be an appropriate method to detect the identity of the catalytic product of PcpB.

Under newly designed experimental conditions, we showed unambiguously that TCHQ rather than TCBQ was the catalytic product of PcpB. Then, two important questions that are needed to be addressed are what role PcpD plays and how TCBQ is produced during the biodegradation of PCP, since previous studies by both Dai et al. and our group confirmed that PcpD was indeed a TCBQ reductase instead of a monooxygenase reductase in spite of its low but statistically significant activity $[11,29]$. To answer these two questions, we decided to analyze the published study results on the pcpD-knockout strain of S. chlorophenolicum ATCC 39723 [11].

The $p c p D$-knockout strain of ATCC 39723 was able to degrade PCP at lower $(100 \mu \mathrm{M})$ but not higher $(300 \mu \mathrm{M})$ 
concentrations [11]. Three explanations were provided by Dai et al. for this phenomenon [11]. The first explanation was that the absence of PcpD resulted in accumulation of the toxic TCBQ that overcame the bacterial cells at higher concentrations of PCP (such as $300 \mu \mathrm{M}$ ). If the explanation were valid, we would expect a deceleration of the degrading rate even at lower concentrations of PCP (such as $100 \mu \mathrm{M}$ ) because PcpB was inhibited by TCBQ in a concentrationdependent manner in the range of $0-80 \mu \mathrm{M}$ and lost almost all of its catalytic activity at $80 \mu \mathrm{M}$ of TCBQ [11]. However, the PCP degrading rate of the $p c p D$-knockout strain was about the same throughout the whole degradation process in the presence of $100 \mu \mathrm{M}$ of PCP [11], indicating that TCBQ was not accumulating within the bacterial cells. The second explanation was that PcpD might be involved in the bacterial response towards the toxicity of PCP or its metabolites, and the third explanation was that the knockout of gene $p c p D$ might alter the expression level of the regulatory gene $p c p R$. But currently there are no experimental evidences available to support these two explanations.

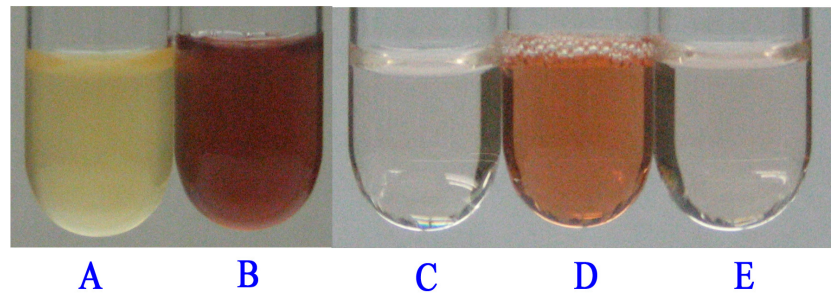

Fig. (7). Peroxidase activity assay of the $S$. chlorophenolicum strain ATCC 39723 cell culture and its cell lysate supernatant. (A). 1.5 $\mathrm{mL}$ bacterial cell culture $+1.5 \mathrm{~mL}$ reaction mixture containing $1 \%$ pyrocatechol; $(\mathbf{B}) .1 .5 \mathrm{~mL}$ bacterial cell culture $+1.5 \mathrm{~mL}$ reaction mixture containing $1 \%$ pyrocatechol and $1.5 \% \mathrm{H}_{2} \mathrm{O}_{2} ;(\mathbf{C}) .300 \mu \mathrm{L}$ of $50 \mathrm{mM}$ phosphate buffer, $\mathrm{pH} 7.0+1.5 \mathrm{~mL}$ reaction mixture containing $1 \%$ pyrocatechol and $1.5 \% \mathrm{H}_{2} \mathrm{O}_{2} ;$ (D). $300 \mu \mathrm{L}$ of cell lysate supernatant $+1.5 \mathrm{~mL}$ reaction mixture containing $1 \%$ pyrocatechol and $1.5 \% \mathrm{H}_{2} \mathrm{O}_{2}$; and (E). $300 \mu \mathrm{L}$ of boiled cell lysate supernatant + $1.5 \mathrm{~mL}$ reaction mixture containing $1 \%$ pyrocatechol and $1.5 \%$ $\mathrm{H}_{2} \mathrm{O}_{2}$.

Compared to the wild-type, the $p c p D$-knockout strain showed a much slower degradation rate at $100 \mu \mathrm{M}$ of PCP [11], implying that there was a small amount of TCBQ in the bacterial cells. However, the almost unchanged PCP degradation rate suggested that the in vivo concentration of TCBQ was constant. It was likely that TCBQ was produced by other enzymes rather than $\mathrm{PcpB}$ and/or by non-enzymatic oxidation of TCHQ, because TCBQ would accumulate to higher concentrations, inhibit the rate-limiting enzyme $\mathrm{PcpB}$, and decrease the PCP degradation rate if it were produced by PcpB. Taking into consideration that PCP could be converted to TCBQ in vivo by peroxidases in fungi [30] and in vitro by horseradish peroxidase $[31,32]$, we suspected that TCBQ was also produced from PCP by at least one peroxidase in $S$. chlorophenolicum strain ATCC 39723. We thus measured the peroxidase activity of the cell culture of strain ATCC 39723 and the supernatant of the bacterial cell lysate (Fig. 7). Peroxidases were observed to be consistently expressed and did not require PCP induction in the strain ATCC 39723, implying that the conversion of PCP to TCBQ by peroxidases was non-specific. The peroxidases might also non- specifically oxidize TCHQ, the catalytic product of PcpB, to TCBQ. Based on the above observation, we hypothesized that PcpD acted as a protective enzyme against the cytotoxicity caused by TCBQ rather than as a PCP-degradation enzyme, because TCBQ has been shown to be extremely toxic to $E$. coli spheroplasts at concentrations lower than 1 $\mu \mathrm{M}$ [9]. Our current hypothesis can readily explain the experimental results on the $p c p D$-knockout strain of ATCC 39723. At lower concentrations of PCP (such as $100 \mu \mathrm{M}$ ), only a small amount of TCBQ was produced non-specifically by the peroxidases, causing a partial inhibition of $\mathrm{PcpB}$ but not high toxicity to the bacterial cells. As PCP was increased to higher concentrations (such as $300 \mu \mathrm{M}$ ), more TCBQ was produced by the peroxidases, leading to severe toxicity to the bacterial cells and complete inhibition of the bacterial growth. Further studies, including identifying and cloning the peroxidases, are required to fully understand the PCP biodegradation pathway and the cyto-protection mechanism in $S$. chlorophenolicum.

\section{CONCLUSION}

In the current study, we showed that chemical reagents $\mathrm{NADPH}$, ethyl acetate and GSH were capable of shifting the redox-equilibrium between TCHQ and TCBQ. Under newly designed experimental conditions, TCHQ rather than TCBQ was identified unambiguously to be the catalytic product of PcpB. Re-analysis of the study results on the $p c p D$-knockout strain of S. chlorophenolicum ATCC 39723 implicated PcpD as a protective enzyme against the cyto-toxicity of TCBQ rather than as a PCP-degradation enzyme.

\section{ACKNOWLEDGEMENTS}

This work was supported by a Discovery Grant from the Natural Sciences and Engineering Research Council of Canada, a New Investigator Establishment Grant and a New Investigator Equipment Grant from the Saskatchewan Health Research Foundation, a New Opportunities Fund from the Canada Foundation for Innovation, a Start-Up Operating Grant and a Start-Up Equipment Grant from the University of Saskatchewan, and a Research Trust Grant from the College of Pharmacy and Nutrition, University of Saskatchewan. We would also like to thank Dr. Shelley D. Copley of the University of Colorado at Boulder for providing us the $E$. coli M15 cells over-expressing the recombinant $\mathrm{PcpB}$ and Dr. Jim Fang of the College of Pharmacy and Nutrition for his help with the HPLC analysis and valuable suggestions.

\section{REFERENCES}

[1] Frank R, Braun HE, Ripley BD, Clegg BS. Contamination of rural ponds with pesticide, 1971-85, Ontario, Canada. Bull Environ Contam Toxicol 1990; 44: 401-409.

[2] McAllister KA, Lee H, Trevors JT. Microbial degradation of pentachlorophenol. Biodegradation 1996; 7: 1-40.

[3] Ingram LL Jr, Tarlton K. Effect of physical properties of pentachlorophenol and creosote components on vaporization from treated wood: Review of prior data. Forest Prod J 2005; 55: 86-89.

[4] Thompson TS, Treble RG, Mariasegaram M. Determination of atmospheric contamination by pentachlorophenol using pine needles located near treated utility pole storage sites. Bull Environ Contam Toxicol 1997; 59: 548-555.

[5] Miyauchi K, Adachi Y, Nagata Y, Takagi Y. Cloning and sequencing of a novel meta-cleavage dioxygenase gene whose product is 
involved in degradation of $\gamma$-hexachlorocyclohexane in Sphingomonas paucimobilis. J Bacteriol 1999; 181: 6712-6719.

[6] Xun L, Topp E, Orser CS. Diverse substrate range of a Flavobacterium pentachlorophenol hydroxylase and reaction stoichiometries. J Bacteriol 1992; 174: 2898-2902.

[7] Xun L, Orser CS. Purification and properties of pentachlorophenol hydroxylase, a flavoprotein from Flavobacterium sp. strain ATCC 39723. J Bacteriol 1991; 173: 4447-4453.

[8] Xun L, Topp E, Orser CS. Purification and characterization of a tetrachloro-p-hydroquinone reductive dehalogenase from a Flavobacterium sp. J Bacteriol 1992; 174: 8003-8007.

[9] McCarthy DL, Claude AA, Copley SD. In vivo levels of chlorinated hydroquinones in a pentachlorophenol-degrading bacterium. Appl Environ Microbiol 1997; 63: 1883-1888.

[10] Copley SD. Evolution of a metabolic pathway for degradation of a toxic xenobiotic: the patchwork approach. Trends Biochem Sci 2000; 25: 261-265.

[11] Dai M, Rogers JB, Warner JR, Copley SD. A previously unrecognized step in pentachlorophenol degradation in Sphingobium chlorophenolicum is catalyzed by tetrachlorobenzoquinone reductase (PcpD). J Bacteriol 2003; 185: 302-310.

[12] Cai M, Xun L. Organization and regulation of pentachlorophenoldegrading genes in Sphingobium chlorophenolicum ATCC 39723. J Bacteriol 2002; 184: 4672-4680.

[13] Kiefer PM Jr, Copley SD. Characterization of the initial steps in the reductive dehalogenation catalyzed by tetrachlorohydroquinone dehalogenase. Biochemistry 2002; 41: 1315-1322.

[14] Kiefer PM Jr, McCarthy DL, Copley SD. The reaction catalyzed by tetrachlorohydroquinone dehalogenase does not involve nucleophilic aromatic substitution. Biochemistry 2002; 41: 1308-1314.

[15] Warner JR, Lawson SL, Copley SD. A mechanistic investigation of the thiol-disulfide exchange step in the reductive dehalogenation catalyzed by tetrachlorohydroquinone dehalogenase. Biochemistry 2005; 44: 10360-10368.

[16] Xun L, Topp E, Orser CS. Confirmation of oxidative dehalogenation of pentachlorophenol by a Flavobacterium pentachlorophenol hydroxylase. J Bacteriol 1992; 174: 5745-5747.

[17] Topp E, Xun L, Orser CS. Biodegradation of the herbicide bromoxynil (3,5-dibromo-4-hydroxybenzonitrile) by purified pentachlorophenol hydroxylase and whole cells of Flavobacterium sp. strain ATCC 39723 is accompanied by cyanogenesis. Appl Environ Microbiol 1992; 58: 502-506.

[18] Chang HC, Compadre RL, Lloyd RV, Freeman JP, Samokyszyn VM. Nonenzymatic reduction of tetrachloro-1, 4-benzoquinone by reduced nicotinamide adenine dinucleotide phosphate in an aqueous system. Biochem Biophys Res Commun 1996; 220: 1043-1048.

[19] Gibbs DE. Benzoquinone and hydroquinone derivatives for use as insect feeding deterrents. U.S. Patent 5780515. 1998 March.

[20] Koskiniemi H, Metsä-Ketelä HM, Dobritzsch D, et al. Crystal structures of two aromatic hydroxylases involved in the early tailoring steps of angucycline biosynthesis. J Mol Biol 2007; 372: 633648.

[21] Thompson JD, Higgins DG, Gibson TJ. CLUSTAL W: improving the sensitivity of progressive multiple sequence alignment through sequence weighting, position-specific gap penalties and weight matrix choice. Nucleic Acids Res 1994; 22: 4673-4680.

[22] Marti-Renom MA, Stuart A, Fiser A, Sánchez R, Melo F, Sali A. Comparative protein structure modeling of genes and genomes. Annu Rev Biophys Biomol Struct 2000; 29: 291-325.

[23] Laskowski RA, McArthur MW, Moss DS, Thornton JM. PROCHECK: A program to check the stereochemical quality of protein structures. J Appl Cryst 1993; 26: 283-291.

[24] Sippl MJ. Recognition of errors in three-dimensional structures of proteins. Proteins 1993; 17: 355-362.

[25] Luthy R, Bowie JU, Eisenberg D. Assessment of protein models with three-dimensional profiles. Nature 1992; 356: 83-85.

[26] Tjeerdema RS, Crosby DG. Disposition and biotransformation of pentachlorophenol in the red abalone (Haliotis rufescens). Xenobiotica 1992; 22: 681-690.

[27] Nakamura T, Motoyama T, Hirono S, Yamaguchi I. Identification, characterization, and site-directed mutagenesis of recombinant pentachlorophenol 4-monooxygenase. Biochim Biophys Acta 2004; 1700: 151-159.

[28] Kung KH, McBride MB. Electron transfer processes between hydroquinone and iron oxides. Clays Clay Minerals 1988; 36: 303-309.

[29] Chen L, Yang J. Biochemical characterization of the tetrachlorobenzoquinone reductase involved in the biodegradation of pentachlorophenol. Int J Mol Sci 2008; 9: 198-212.

[30] Reddy GVB, Gold MH. Degradation of pentachlorophenol by Phanerochaete chrysosporium: intermediates and reactions involved. Microbiology 2000; 146: 405-413.

[31] Samokyszyn VM, Freeman JP, Maddipati KR, Lloyd RV. Peroxidase-catalyzed oxidation of pentachlorophenol. Chem Res Toxicol 1995; 8: 349-355.

[32] Vaidyanathan VG, Villalta PW, Sturla SJ. Nucleobase-dependent reactivity of a quinone metabolite of pentachlorophenol. Chem Res Toxicol 2007; 20: 913-919.

(C) Yunyou Su et al.; Licensee Bentham Open.

This is an open access article licensed under the terms of the Creative Commons Attribution Non-Commercial License (http://creativecommons.org/licenses/by$\mathrm{nc} / 3.0 /$ ) which permits unrestricted, non-commercial use, distribution and reproduction in any medium, provided the work is properly cited. 